\title{
Isolation and purification of plasma albumin from human blood samples
}

\author{
J. T. UGYE ${ }^{1 *}$, A. UZAIRU ${ }^{2}$, S. O. IDRIS ${ }^{2}$ and H. O. KWANASHIE ${ }^{3}$ \\ I*Department of Chemistry, Benue State University, P.M.B 102119, Makurdi, Nigeria. \\ ${ }^{2}$ Department of Chemistry, Ahmadu Bello University, Zaria, Nigeria. \\ ${ }^{3}$ Department of Pharmacology and Therapeutics ,Ahmadu Bello University, Zaria, Nigeria. \\ *Corresponding author, E-mail: torugye2007@yahoo.co.uk; Tel: +2348069519202
}

\begin{abstract}
This study isolated plasma albumin from human blood samples using cold $19 \% \mathrm{v} / \mathrm{v}$ ethanol as well as containing $0.6 \% \mathrm{v} / \mathrm{v}$ trichloro acetic acid for the isolation of albumin from blood serum or plasma using organic solvents after standing for $5 \mathrm{hr}$. The precipitated plasma albumin was then fractionated using $90 \%$ ethanol containing $0.14 \%$ hydrochloric and was finally neutralized with $0.5 \mathrm{~mol} . \mathrm{dm}^{-3} \mathrm{NaOH}$ to obtain a white flocculent precipitate of plasma albumin which was dried over $\mathrm{P}_{2} \mathrm{O}_{5}$ to obtain a percentage recovery of $1.36 \%$. The dried isolated plasma albumin was further characterized for purity using protein analysis, optical rotation , solubility and denaturation tests. The results show the plasma album contained $63.67 \%$ protein , with specific rotation at $[\alpha]_{598}{ }^{32}$ at $\mathrm{pH} 7.2$ of $8^{0}$ and gradually dissolved in acidified water and ethanol. The plasma albumin was also found to be slightly turbid when dissolved in water indicating some degree of denaturation. (C) 2011 International Formulae Group. All rights reserved.
\end{abstract}

Keywords: Plasma albumin, isolation, fractionation, Characterization , 90\%ethanol, $0.14 \% \mathrm{HCl}$.

\section{INTRODUCTION}

It has long been known that trichloro acetic acid precipitates of certain proteins dissolve in methanol whereas those of other proteins do not (Michael, 1968). Several authors (Kallee et al., 1957; Korner et al., 1956; Schwert, 1957; Rotraut,1975) have previously investigated the properties of albumin after treatment with trichloroacetic acid and alcohol or acetone and have arrived at the conclusion that the albumin, after recovery was still in the native state, as judged by its physicochemical properties and by its unchanged antigenic properties, but that it has acquired a slightly changed susceptibility towards proteolytic enzymes (Jarnefelt 1961; Ram et al., 1958).

A more detailed study of the behaviour of the main blood proteins and some other proteins has shown that the solubilising action in suitable organic solvents on albumin, but not on globulins, is shared by a number of other acids (Michael, 1968). Some acids were found to be unable to prevent damage to the albumin in the organic solvents, whereas others preserved the albumin in a condition that is more nearly related to the native state. This has enabled a process of separation of blood proteins to be developed which gives albumin of a high grade of purity, in high yields. In the study conducted by Michael, 
methanol and $0.1 \mathrm{~mol} \mathrm{dm}^{-3} \mathrm{HCl}$ were used to investigate the properties albumin obtained from human serum.

This present study therefore employed Ethanol and $0.14 \% \mathrm{HCl}$ acid to undertake the isolation and fractionation of whole human blood to obtain plasma albumin with the hope of obtaining high purity and as a way of exposing the efficacy of Ethanol as another of the organic solvents that can be used to isolate plasma albumin.

\section{MATERIALS AND METHODS}

The Human blood samples were graciously provided by the Federal Medical Centre Makurdi after obtaining an ethical committee approval and was pre-treated to remove haemoglobin the major contaminant in human plasma albumin.

This was followed by fibrinogen, globulin and the plasma albumin fractionation using ethanol with some modifications as follows:

The whole blood samples, $600 \mathrm{~cm}^{3}$ arranged in three batches, were taken in $\mathrm{K}_{2}$ EDTA sample bottles and centrifuged for 30 minutes at $2500 \mathrm{r} / \mathrm{min}$. Then the plasma fraction was carefully pipetted out using a teat pipette into a pre weighed beaker $\left(215 \mathrm{~cm}^{3}\right)$ aliquot and was finally weighed to obtain a $183.72 \mathrm{~g}$ plasma sample. Then, the $\mathrm{pH}$ of the plasma was adjusted to 7.2 with acetate buffer $\left(4\right.$ mol. $\mathrm{dm}^{-3}$ sodium acetate and 10 mol.dm ${ }^{-3}$ acetic acid, $\mathrm{pH} 4.0$ ).

Next $20 \mathrm{~cm}^{3}$ of a mixture of $19 \% \mathrm{v} / \mathrm{v}$ cold ethanol as well as containing $0.6 \% \mathrm{v} / \mathrm{v}$ trichloro acetic acid were slowly added under homogenization. This mixture was kept at 4.0 ${ }^{\circ} \mathrm{C}$ in a refrigerator for 30 minutes and further homogenized for 20 minutes in order to obtain complete haemoglobin precipitation. After this step, the plasma was left overnight in a refrigerator at $\quad 0 \quad{ }^{\circ} \mathrm{C}$ for $\quad \gamma$-globulin precipitation. The precipitate consisting of haemoglobin and $\gamma$-globulin were removed by centrifugation at 2,500 r/min for 10 minutes and was discarded to obtain a supernatant I. The $\mathrm{pH}$ of the supernatant was adjusted to 6.0 with acetate buffer solution, $\mathrm{pH} 4.0$, under homogenization for 30 minutes and the precipitate left to stand for 3-6 hrs to precipitate $\alpha$ - and $\beta$-globulin, which were removed by centrifugation as described above and discarded to obtain a plasma, here after referred to as supernatant II.

The supernatant II was then mixed at room temperature with $10 \mathrm{~cm}^{3}$ of $90 \%$ ethanol containing $0.14 \%$ hydrochloric. After 30 minutes of vigorous stirring, the mixture was centrifuged, the liquors were removed, and the precipitated globulins washed in the centrifuge with a volume of $90 \%$ ethanol equal to half the original volume of serum or plasma. The liquor and washings were combined to obtain a clear solution.

The clear solutions thus obtained were neutralized with $10 \mathrm{~cm}^{3}$ of 0.5 mol. $\mathrm{dm}^{-3} \mathrm{NaOH}$ to an apparent end point of $\mathrm{pH}$ 6 , whereby a white flocculent precipitate of albumin was formed. The precipitated albumin was allowed to settle, was freed from the liquor by decantation and centrifuging, and was washed, while still in the centrifuge, successively twice with ethanol and twice with diethyl ether, was dried in air and finally in vacuo over $\mathrm{P}_{2} \mathrm{O}_{5}$ at room temperature, and weighed. The albumin was thus obtained in the form of a free-flowing, non-hygroscopic powder.

\section{Characterization of isolated plasma albumin \\ Protein analysis}

The protein content of the albumin preparations was determined using the Kjeldahl method (AOAC, 1980). The percentage Protein was calculated from the nitrogen figures by using the factor 6.25 . 


\section{The procedure was follows}

The samples were digested with $20 \mathrm{~cm}^{3}$ of concentrated $\mathrm{H}_{2} \mathrm{SO}_{4}, 150 \mathrm{~cm}^{3}$ of $\mathrm{NaOH}$ (40\%), $10 \mathrm{~g}$ of $\mathrm{K}_{2} \mathrm{SO}_{4}$ and $0.5 \mathrm{~g}$ of $\mathrm{CuSO}_{4}$. Five $\left(5 \mathrm{~cm}^{3}\right)$ of the digest was placed into a micro-Kjeldahl distillation apparatus and 150 $\mathrm{cm}^{3}$ of the $(40 \%) \mathrm{NaOH}$ was added to make the solution strongly alkaline. The Ammonia was distilled into $5 \mathrm{~cm}^{3}$ of boric acid indicator in a titrating flask until above $45 \mathrm{~cm}^{3}$ of the distillate was collected. Titration was done with $0.01 \mathrm{~mol} \mathrm{dm}^{-3} \mathrm{HCl}$ to obtain a light green end point.

\section{Solubility and denaturation tests Procedure}

$0.005 \mathrm{~g}$ of the specimen were mixed with $100 \mathrm{~cm}^{3}$ water to give a $0.005 \%$ solution of the albumin, then $0.1 \mathrm{~mol} \mathrm{dm}{ }^{-3} \mathrm{NaOH}$ was added drop by drop until the $\mathrm{pH}$ was 7.4. The rate and completeness of dissolution were observed. The same procedure was carried out using commercially processed egg and Bovine albumin samples and the rate of dissolution observed. This test, in which the solubility of albumin at different $\mathrm{pH}$ values is examined, is similar to one of the methods described as a criterion for the native state or degree of denaturation of albumin.

\section{Denaturation tests}

The appearance of turbidity or precipitate when $0.1 \mathrm{~mol} \mathrm{dm}^{-3} \mathrm{NaOH}$ is added to a protein sample is a measure of its native form (Ehrenpreis et al., 1957). When precipitation or turbidity occurred, it is usually taken as an indication of some degree of denaturation of the protein. Invariably, any such turbidity or precipitate is reported to re dissolve at $\mathrm{pH} 7$ the protein.

\section{Procedure}

$0.01 \mathrm{~g}$ each of the isolated plasma albumin sample along with commercially processed egg and Bovine albumin samples were taken in a beaker and $5 \mathrm{~cm}^{3}$ of $0.1 \mathrm{~mol}$ $\mathrm{dm}^{-3} \mathrm{NaOH}$ were added to each beaker at varying $\mathrm{pH}$ of 5.0, 6.0 7.0 and 8.0 and was allowed to stand for ten minutes. After the time interval, each of the samples was examined for appearance of precipitate or turbidity.

\section{Optical rotation measurement by use of a polarimeter \\ Optical rotation is the turning of the} plane of linearly polarized light about the direction of motion as the light travels through certain materials. It is found to occur in solutions of chiral molecules sugars such as sucrose (sugar), solids with rotated crystal planes such as quartz, and spin -polarized gases of atoms or molecules.

Generally, the refractive index is found to depend on the wavelength. The variation in rotation with the wavelength of the light is called optical rotator dispersion (ORD). In summary, the degree of rotation depends on the colour of the light (the yellow sodium D line near $589 \mathrm{~nm}$ wavelength is commonly used for measurements), the path length $L$ and the properties of the material (e.g. specific rotation and concentration). For a pure substance in solution, it is fund that if the colour and path length are fixed and the specific rotation is known, the observed rotation can be used to calculate the concentration. This usage makes polarimeter a versatile tool of great importance to those who trade in or use sugar syrups in bulk (Eugene, 1998).

In this study, solutions $(0.005 \%, \mathrm{w} / \mathrm{v})$ of the samples were adjusted accurately to the desired $\mathrm{pH}, 7.4$ by the addition of $0.1 \mathrm{~mol}$ $\mathrm{dm}^{-3} \mathrm{NaOH}$, and examined for their optical rotation, $[\alpha]_{\mathrm{D}}{ }^{\mathrm{t}}$. at temperature of $32{ }^{\circ} \mathrm{C}$.

\section{Procedure}

$20 \mathrm{~cm}^{3}$ of distilled water were measured in the observation tube of the polarimeter and the blank reading observed 
and recorded that is when maximum darkness occurred and was recorded as $\theta_{1}$. The distilled water in the observation tube was replaced with the sample solutions (0.005 $\mathrm{g})$ of Bovine Albumin, Egg York Albumin, and the two isolated plasma albumin samples respectively and again the angle of rotation measured and was recorded $\theta_{2}$. The angle $\left(\theta_{2-} \theta_{1}\right)$ was recorded as the angle of rotation. Triplicate readings for each of the four samples were made and the angle of rotation obtained from the relation $\left(\theta_{2-} \theta_{1}\right)$.

The specific rotation for each of the samples was calculated using the relation:

$[\alpha]_{\mathrm{D}}^{\mathrm{T}}=\underline{100} \alpha$

LC

Where: $\mathrm{C}=$ Concentration of the optically active matter in a sample $(\mathrm{mg} / \mathrm{ml})$;

$\alpha=$ specific rotation;

$\mathrm{L}=$ length of observation tube $1 \mathrm{dm}=100 \mathrm{~mm}$;

$\mathrm{D}=$ wavelength of sodium $\mathrm{D}$-line $=598 \mathrm{~nm}$;

$\mathrm{T}=$ temperature at which measurement was made.

\section{RESULTS AND DISCUSSION}

The percentage recovery of the plasma albumin obtained from the method used in this study was very low (2.4 g), about $1.306 \%$. However, the quality of plasma albumin obtained was found to be active and pure in its native state and slightly denatured from the results of the analysis carried out. Also, the method allowed for isolation and recovery of native state plasma albumin for analysis from simple and available reagents and equipment without resulting to the expensive and time consuming chromatographic procedures

From the results of the study, it can be observed that all the albumin samples have specific rotation of $8^{0}$ except in the case of bovine albumin that has a value of $10^{0}$ slightly higher than that of the plasma albumin.

\section{Conclusion}

This study was aimed at isolating, precipitating and purifying the plasma albumin from whole blood using cold ethanol and $0.14 \% \mathrm{HCl}$ in place cold methanol and acetic acid. The results indicated that $2.4 \mathrm{~g}$ of the plasma albumin was obtained using these solvent combinations with a percentage recovery of approximately $1.31 \%$.

The plasma albumin on characterization showed the following characteristics: Protein content, $63.67 \%$, specific rotation of $8^{\circ}$ and was found to gradually dissolve in acidified water and ethanol as well as slightly denatured.

These results show that the isolated plasma albumin was still in its native state. Also, in spite of the very low recovery, the method can be adjudged and effective for small sample investigations. It also shows that plasma albumin could be isolated using ethanol and $0.14 \% \mathrm{HCl}$ in absence of the reported methanol and acetic acid solvent combination within a short time with ease in the absence of the state of art HPLC and other recently developed chromatographic equipment.

Table 1: Summary of results.

\begin{tabular}{ll}
\hline Parameters & Results \\
\hline Percentage recovery & $2.4 \mathrm{~g},(1.31 \%)$ \\
Protein analysis & $63.67 \%$ \\
Specific optical activity(degrees) & $8^{0}$ \\
Denaturation test & Slightly denatured \\
Solubility & Gradually dissolves in acidified water and ethanol. \\
\hline
\end{tabular}




\section{ACKNOWLEDGEMENTS}

We are highly indebted to the Management and Staff of Federal Medical Centre Makurdi, for granting the ethical approval as well as donating the blood samples used in this study. We also wish to greatly appreciate the staff of the Biochemistry Department, Benue State University College of Health Science and those of the Microbiology Department Ahmadu Bello University, Zaria for their support and provision of the facilities /equipment that were used in this study.

\section{REFERENCES}

A.O.A.C. 1980. Official Methods of Analysis (13th edn). Association of Official Analytical Chemists. Springer, Berlin Heidelberg: New York., Washington, D. C. 460-516.

Ehrenpreis S, Maurer PH, Ram JS. 1957. Modified bovine serum albumin. I. Preparation and physicochemical studies of some derivatives. Arch. Biochem., 67: I78.

Eugene Hecht. 1998. Optics (3rd edn). Addison-Wesley.

Jarnefelt J. 1961. Isolation of bovine serum albumin. Biochim. Biophy. Acta, 48: 104.

Kallee E, Lohss F, Oppermann W. 1957. Zeitsch.Nat rf, 126: 777-783.27.
Korner A, Debro JR. 1956. Modified bovine serum albumin -V. Immunochemical and other studies of bovine serum albumin, after precipitation with trichloroacetic acid and solution in ethanol. Nature, 178: 1067.

Michael SE. 1968.The isolation of albumin from blood se rum or plasma by means of organic solvents. Biochem. J., 82: 212218.

Rotraut G, Hahn E, Nowac H, Timpl R. 1975. Immunochemistry (Vol. 12). Pergamon Press; 893-897.

Schwert GW. 1957. Immunochemistry of bovine fibrinogen-I. Immunogenic activity and diversity of antigenic determinants of reduced and carboxymethylated $\alpha, \beta$ and $\gamma$ chain. $J$. Amer. Chem. Soc., 79: 139.

Tanaka K, Sawatani E, Shigueoka EM, Dias GA, Nakao HC, Arasiro F. 2001. Isolation of bovine plasma albumin by Liquid Chromatography and its polymerization for use in Immunohematology. Brazillian Journal of Medical and Biological Research, 34: 977-983. 